Research Article

\title{
Effects of Parameter Uncertainties on Interaction between Submarine Telecommunication Cables and Lateral Seabed Movements
}

\author{
Cuiwei Fu ${ }^{(D)},{ }^{1}$ Xiaogang Qin ${ }^{D},{ }^{2}$ and Yu Wang ${ }^{2}{ }^{2}$ \\ ${ }^{1}$ State Key Laboratory of Coastal and Offshore Engineering, Dalian University of Technology, Dalian 116024, China \\ ${ }^{2}$ Department of Architecture and Civil Engineering, City University of Hong Kong, Tat Chee Avenue, Kowloon, Hong Kong \\ Correspondence should be addressed to Xiaogang Qin; xiaogqin@cityu.edu.hk
}

Received 2 June 2020; Revised 19 July 2020; Accepted 24 July 2020; Published 20 August 2020

Academic Editor: Peixin Shi

Copyright (c) 2020 Cuiwei Fu et al. This is an open access article distributed under the Creative Commons Attribution License, which permits unrestricted use, distribution, and reproduction in any medium, provided the original work is properly cited.

Submarine telecommunication cables are the physical backbone of the Internet. They are often buried shallowly beneath seabed and affected by seabed movements. Due to the long distance of cables and the complexity of submarine environment, interaction between cables and seabed movements inevitably involves various parameter uncertainties. However, effects of parameter uncertainties on submarine cable responses to seabed movements have not been fully investigated. This paper aims to address this problem using random finite element method (RFEM) that integrates finite element (FE) analysis with Monte Carlo simulation (MCS). First, deterministic FE analysis is performed to investigate cable responses to lateral seabed movements. Then MCS is implemented to study the effects of parameter uncertainties on cable responses. Statistical analysis of the MCS results is performed to prioritize the effects of parameter uncertainties on cable damage probability. Random field is also used to model spatial variability of soil parameters. Effect of the correlation length on cable damage probability is investigated. The results show that uncertainty of the anchored cable length $L_{a}$ has the most significant effect on cable damage probability, while the effects of uncertainties in soil friction angle $\phi$ and effective unit weight $\gamma^{\prime}$ are minor. Ignoring spatial variability of soil parameters may lead to significant misjudgment of cable damage risk.

\section{Introduction}

The Internet telecommunication is becoming indispensable to people's daily lives. Nowadays about $99 \%$ of Internet telecommunication is transmitted via fiber-optic submarine telecommunication cables, which have been the physical backbone of the entire cyber world [1]. Submarine telecommunication cables are often buried shallowly beneath the seabed when they are near shore or placed directly on the ocean floor in the deep sea. Submarine cables might undergo self-burial in zones of high sediment accumulation [2]. Meanwhile, seabed movements induced by earthquakes often occur near the boundaries of tectonic plates, which can lead to structural damage of submarine telecommunication cables, interfering in the transmission of Internet data and impeding the economics of the related countries [3]. For example, 22 submarine telecommunication cables were reported broken during the 2006 Pingtung earthquake in Taiwan, and 6 to 9 breaks were recorded during the 2010 Jiashian earthquake in Taiwan [4]. However, due to the long transmitting distance of cables and complex ocean conditions, the failure mechanism and reliability of submarine cables subjected to earthquake-induced geohazards are still unclear, which severely impedes the maintenance and protection of international telecommunications.

Since seabed soil is the medium for connecting seismic hazards with submarine telecommunication cables, understanding properties of seabed soil is necessary for assessment of seabed movement effects on submarine cables. Uncertainties are inevitably involved in the estimation of seabed soil properties [5]. In addition, the uncertainties in seabed geohazards (e.g., earthquake-induced fault displacement and 
ground movement direction) also need to be considered in the assessment of seismic effects on buried structures. For example, Cheng and Akkar [6] conducted probabilistic risk assessment for the performance of continuous pipelines subjected to permanent fault displacements. However, for the problem of interaction between seabed movements and submarine telecommunication cables, there is little research on assessing the effect of involved parameters uncertainties on cable responses.

This paper aims to investigate the effects of parameter uncertainties on submarine cable responses to lateral seabed movements and evaluate cable damage probability. It starts with the development of deterministic FE model for simulating cable responses to a specific seabed movement. Then MCS is implemented to analyze cable responses considering parameter uncertainties. MCS results are analyzed to prioritize the effects of various parameter uncertainties on cable damage probability. Finally, the effect of spatial variability of soil parameters on cables responses is investigated.

\section{Deterministic Finite Element Modeling of Cable-Seabed Interaction}

2.1. Modeling of Submarine Telecommunication Cables. A submarine telecommunication cable is designed to protect optical fibers from external impact and is responsible for transmitting signals across oceans. Optical fibers are usually confined in a steel tube and then reinforced by highstrength steel wires. The exterior layer of the submarine telecommunication cable is covered by waterproof and corrosion-resistant materials, such as polyethylene (PE) and polypropylene (PP). Based on optical fibers' protection types, submarine telecommunication cables are divided into three categories: light weight (LW) cable, single-armored (SA) cable, and double-armored (DA) cable [7]. SA and DA cables are produced by reinforcing the LW cable with one-layer and two-layer helical steel wires, respectively. A submarine telecommunication cable is manufactured with a designed cable breaking load (CBL), which is the maximum tensile force a cable can withstand [8]. The cable strain under $\mathrm{CBL}$ is the allowable cable strain $\varepsilon_{\text {allo, }}$, which is a critical parameter to judge whether or not the cable will break. Note that CBL differs from the fiberbreaking cable load, which will result in an instantaneous fiber break [8]. This study focuses on the structural response of cables; therefore only CBL is considered in the following analysis.

The precise modeling of the cross section configuration of a telecommunication cable is rather complicated. Therefore, the submarine cable is simplified as a continuous beam element in FE analysis in this study, which considerably reduces the computational cost and facilitates the implementation of MCS in the following sections. The cross section with composite materials is simplified as an equivalent cross section with an equivalent single material. Consider, for example, the SA submarine cables produced by Alcatel-Lucent (see Figure 1) [9]. The inner and outer diameters (i.e., $D_{1}$ and $D_{2}$ ) are $1.9 \mathrm{~mm}$ and $28 \mathrm{~mm}$, respectively. The original cross section can be approximated by an equivalent homogeneous cross section with a single material. The equivalent cross section has the same inner and outer diameters as the original cross section. To obtain the overall mechanical behavior of the submarine cable, the equivalent Young's modulus of the cable, $E_{\text {equ }}$, is calculated as the ratio of the cable tensile stiffness over the equivalent cross section area. The cable tensile stiffness can be calculated as a sum of the tensile stiffnesses of all cable components. The equivalent Young's modulus of the SA cable is estimated as follows: cable tensile stiffness/equivalent cross section area $=38651 \mathrm{kN} / 613 \mathrm{~mm}^{2}=63.06 \mathrm{GPa}$. In addition, CBL for the SA cable is $280 \mathrm{kN}$ based on the manufacturer [9]. Then, the allowable cable strain $\varepsilon_{\text {allo }}$ is calculated as $0.72 \%$.

2.2. Interaction between Cables and Lateral Seabed Movements. As shown in Figure 2, a submarine cable is subjected to seabed movements with an intersection angle $\left(0^{\circ}<\beta \leq 90^{\circ}\right)$ between the seabed movement direction and the cable axial direction. The length of cable considered in the model is denoted as $L_{a}$, which represents the anchored length between two anchor points (i.e., points $B$ and $D$ in Figure 2). In engineering practice, submarine cables may be subjected to bends or local constraints imposed by the sliding of adjacent rocks or soils, resulting in some anchor points along the cables. The cables are then fixed to the seabed at the anchor points due to the increased axial resistance of the sliding rocks or soils. The seabed offset, $\Delta_{s}$, can be projected into an axial component (i.e., $\Delta X=\Delta_{s} \cos \beta$ ) and a transverse horizontal component (i.e., $\left.\Delta Y=\Delta_{s} \sin \beta\right)$. Cable responses to lateral seabed movements are the combined effects of $\Delta X$ and $\Delta Y$. Loads are imposed on the cable through the surrounding soil, which involves the cable-soil interaction in axial and transverse horizontal directions. Using the equivalent cable cross section described in Figure 1, the cable-soil interaction in this study is similar to pipe-soil interaction. As illustrated in Figure 3, the force-displacement relationships of pipesoil interaction in the axial and transverse horizontal directions may be represented using idealized elastoplastic models (i.e., solid lines in Figure 3) [10]. The resistance forces per unit length increase linearly as the displacement increases, until they reach the maximum values $t_{u}$ and $p_{u}$ at the displacements of $x_{u} / 2$ and $y_{u} / 2$, respectively. Then the resistance forces remain constant. Recent research shows that the transverse soil resistance on offshore pipelines partially embedded in soft clay tends to decrease gradually after it reaches the peak value $[11,12]$. This phenomenon also occurs for pipelines buried in dense sand [13], whereas, in medium sand condition, the peak and residual resistances are nearly equal [14]. Since the medium sand condition is considered in this study, the constant assumption recommended by the ALA guidelines can provide a relatively safe estimation on postpeak structural response [15] and is therefore adopted in this study. The maximum axial and transverse horizontal resistance forces (i.e., $t_{u}$ and $p_{u}$, respectively) can be calculated as [10] 

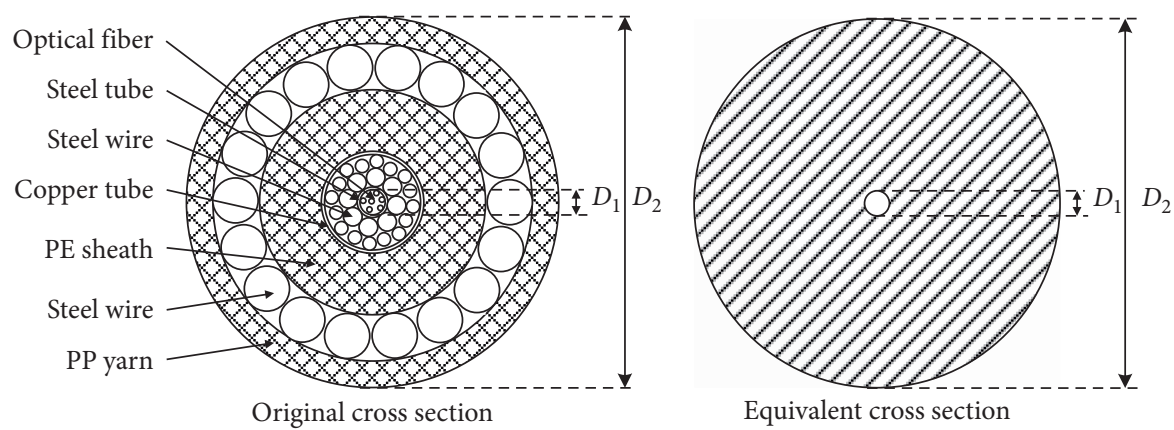

FIgURE 1: Equivalent cross section of the single armored cable.

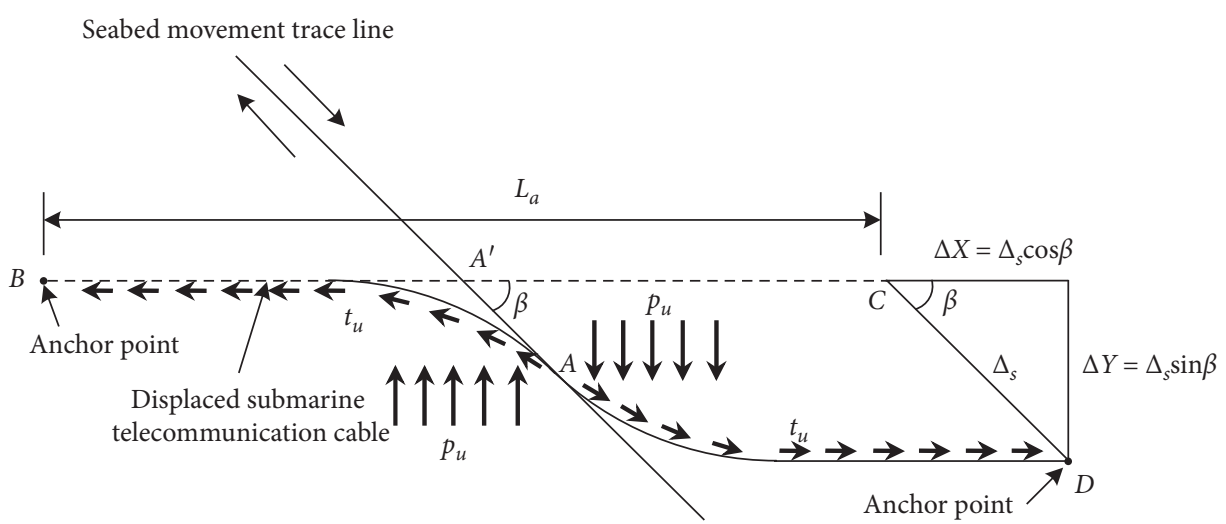

FIgURE 2: Plan view of a submarine telecommunication cable subjected to lateral seabed movements.

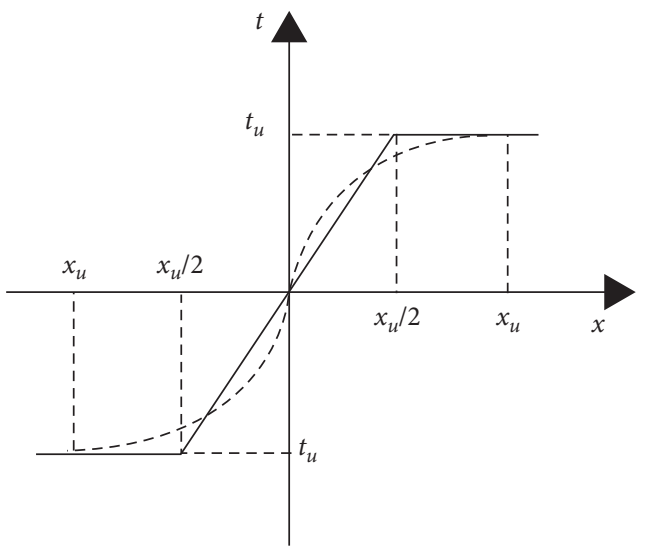

(a)

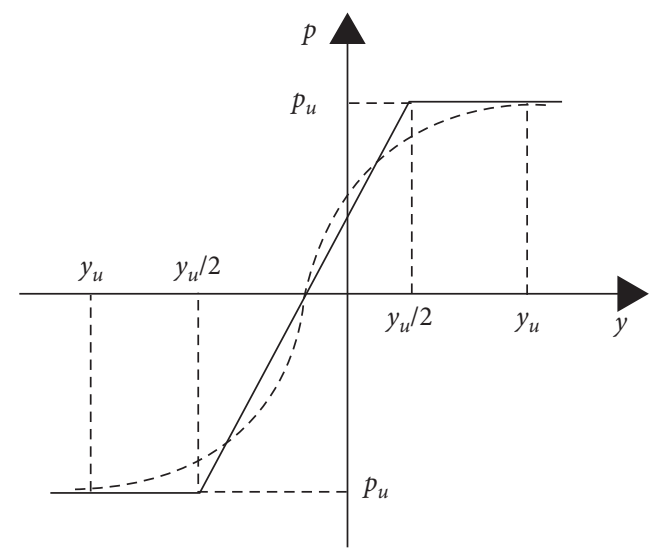

(b)

FIGURE 3: Force-displacement relationships of pipe-soil interaction in (a) axial and (b) transverse horizontal directions (modified after [10]).

$$
\begin{aligned}
t_{u} & =\frac{\pi}{2} D \gamma^{\prime} H\left(1+k_{0}\right) \tan (k \phi), \\
p_{u} & =\gamma^{\prime} H N_{q h} D,
\end{aligned}
$$

where $D$ is the cable/pipe diameter; $\gamma^{\prime}$ is the effective unit weight of soil; $H$ is the depth of soil from the seabed surface to the center of the cable/pipe; $k_{0}$ is the coefficient of earth pressure at rest; $k$ is the reduction factor depending on the outer surface characteristics and hardness of the cable/pipe; $\phi$ is the soil friction angle; and $N_{q h}$ is the horizontal bearing capacity factor for sand. The recommended values of $x_{u}$ and $y_{u}$ are as follows: $x_{u}=3 \mathrm{~mm}$ for dense sand or $x_{u}=5 \mathrm{~mm}$ for loose sand; $y_{u}=0.04(H+D / 2) \leq 0.10 D$ to $0.15 D$ [10].

2.3. Development of Finite Element Model. FE analysis is widely used to investigate the interaction between buried structures and surrounding soils [16-18]. In this study, a simplified FE model is established using the commercial FE software package ABAQUS (Version 6.13) [19] to investigate the submarine cable response to a specific seabed movement. Figure 4 shows an illustrative model of submarine cable responses to lateral seabed movements. The $x$-, $y$-, and $z$-axes 


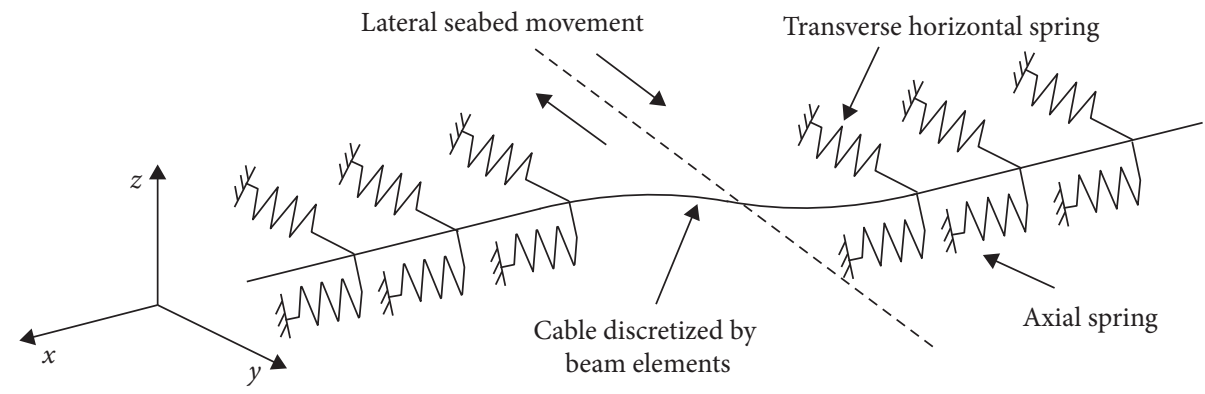

FIGURE 4: Finite element model of submarine telecommunication cable responses to lateral seabed movements.

represent the axial, transverse horizontal, and transverse vertical directions of the cable, respectively. Beam elements are used to model the submarine cable. The cable-soil interaction is simulated using pipe-soil interaction (PSI) elements in ABAQUS, which are formulated according to the ALA guidelines [10] and have been used in previous studies for modeling the interaction between the pipe and surrounding soil [20-23]. As shown in Figure 4, since the lateral seabed movement occurs in a horizontal plan, the PSI elements are characterized using soil springs along axial and transverse horizontal directions to model different cable responses to the axial and transverse horizontal soil movements, respectively. The corresponding nonlinear force-displacement relationships for the soil springs are defined by the ALA guidelines (as shown in Figure 3) [10]. To simulate the lateral seabed movement, the axial and transverse horizontal seabed offset components (i.e., $\Delta X$ and $\Delta Y$ in Figure 2, respectively) are imposed on the PSI elements simultaneously as boundary conditions. In addition, since large rotations or bending deformations may be induced on the cable near the crossing area of seabed movements, the geometric nonlinearity is also considered in the FE analysis. An element size of $0.1 \mathrm{~m}$ is used in the model. Mesh density sensitivity analysis shows that this element size can produce reliable results with acceptable computing cost.

Consider, for example, the SA submarine telecommunication cable described previously. The anchored cable length $L_{a}$ is assumed be $500 \mathrm{~m}$. The cable is buried in soil at a depth of $H=0.5 \mathrm{~m}$. The effective soil unit weight $\gamma^{\prime}$ and critical friction angle $\phi$ are $10.2 \mathrm{kN} / \mathrm{m}^{3}$ and $35^{\circ}$, respectively. The cable is subjected to a seabed offset $\Delta_{s}$ of $4 \mathrm{~m}$. The intersection angle $\beta$ between the cable axial direction and seabed movement is $45^{\circ}$. The coefficient of earth pressure at rest $k_{0}$ in equation (1) is calculated as $k_{0}=1-\sin \phi=0.43$. Considering the relatively smooth polypropylene surface of the cable, the reduction factor $k$ is estimated as 0.6 [10]. According to the design chart of ASCE guidelines, the $N_{q h}$ value is estimated as 22.8. Then, using equations (1) and (2), the maximum axial and transverse horizontal resistance forces are calculated as $t_{u}=123 \mathrm{~N} /$ $\mathrm{m}$ and $p_{u}=3251 \mathrm{~N} / \mathrm{m}$, respectively. $x_{u}$ and $y_{u}$ are estimated as $x_{u}=5 \mathrm{~mm}$ and $y_{u}=0.01 D=2.8 \mathrm{~mm}$, respectively. For this case, the maximum cable strain $\varepsilon_{\max }$ obtained from the FE is $0.66 \%$, which is smaller than the allowable cable strain $\varepsilon_{\text {allo }}$ (i.e., $0.72 \%$ ). It indicates that the cable is safe under the given seabed movement.
2.4. Validation of the FE Analysis. The effectiveness of FEM is usually examined by comparison with model test results $[17,24]$. The developed FE model is validated by a large-scale physical model test. The test is performed in a large-scale split-box test apparatus at City University of Hong Kong with internal dimensions of $5 \mathrm{~m} \times 1 \mathrm{~m} \times 1 \mathrm{~m}$ (length $\times$ width $\times$ height). One half of the box is secured to the ground, and the other part can move along a certain angle with respect to the longitudinal axis of the split-box. The submarine cable is installed in the center of the split-box and displaced with an intersection angle of $70^{\circ}$ between the cable axial direction and soil displacement. For detailed information about the physical model test, we refer the reader to $\mathrm{Fu}$ [25].

Figure 5 shows the experimental and FE simulation results by lines and open points, respectively, including the cable axial strain, bending strain, and total strain. The total strain is the sum of the axial strain and bending strain. Five different soil displacements are simulated (i.e., $\Delta_{s}=50,100$, 150,200 , and $220 \mathrm{~mm}$, respectively). Note that the cable is damaged when $\Delta_{s}=220 \mathrm{~mm}$. Measurement error and installation error are inevitable during the experiment. Besides, the soil resistance and cable model in FEM are derived and simplified based on previous studies. Consequently, differences may exist between the experiment and FEM. However, the orders of magnitude of bending strain from FEM match relatively well with the experimental measurements, both showing that the bending strain only accounted for about $10 \%$ of the total strain. Thus, the difference between FEM and experimental results in bending strain is regarded as acceptable in this study. Figure 5 suggests that the axial strain is predominant in the total cable strain (see Figure 5(c)) and the axial and total strains obtained from FE analysis are in reasonable agreement with the experimental results. Therefore, the developed FE model predicts relatively well the cable strain induced by lateral ground movements. Note that when the FE model is applied to seabed soil, the submerged soil unit weight, instead of total unit weight, is used to calculate axial and transverse horizontal soil resistance forces as indicated by $[11,12]$.

\section{Random Finite Element Model}

3.1. Probabilistic Framework for Assessment of Parameter Uncertainties. Figure 6 illustrates a random finite element modeling framework that integrates FE analysis with MCS to 

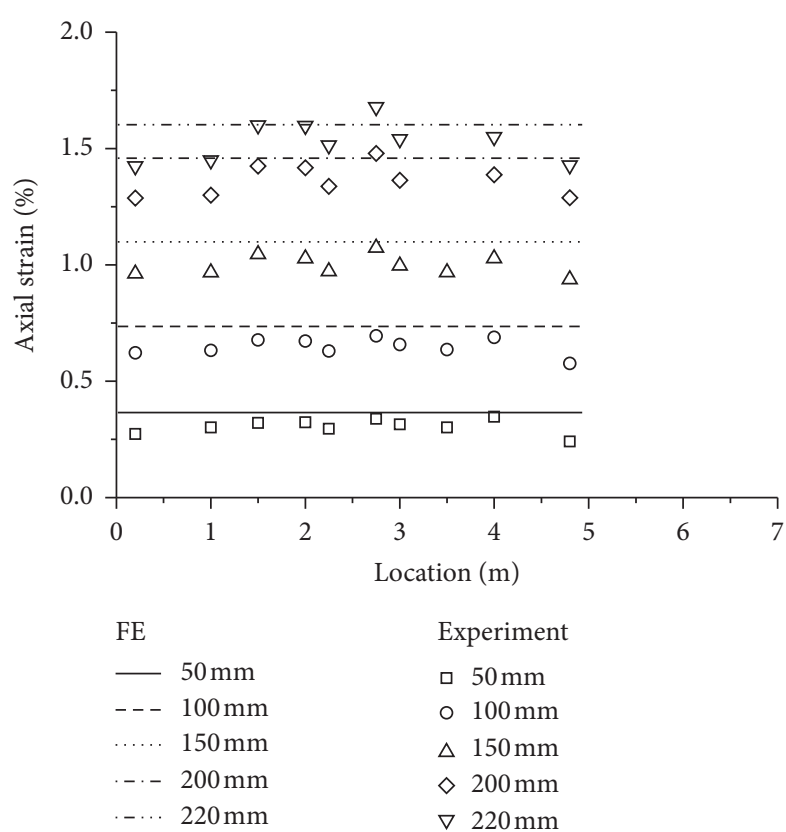

Experiment

$50 \mathrm{~mm}$

○ $100 \mathrm{~mm}$

$\triangle 150 \mathrm{~mm}$

$\diamond 200 \mathrm{~mm}$

$\nabla 220 \mathrm{~mm}$

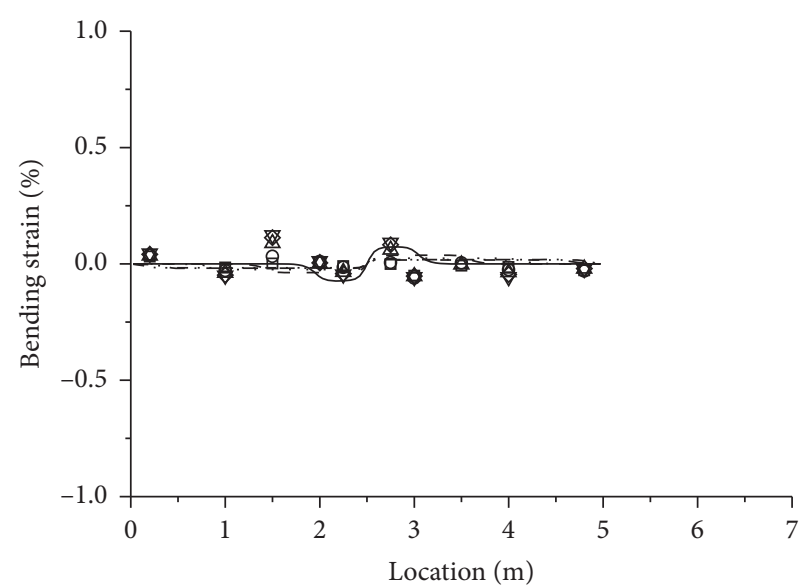

FE

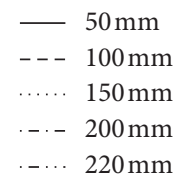

Experiment
$50 \mathrm{~mm}$
- $100 \mathrm{~mm}$
$\triangle 150 \mathrm{~mm}$
$\diamond 200 \mathrm{~mm}$
$\nabla 220 \mathrm{~mm}$

(a)

(b)

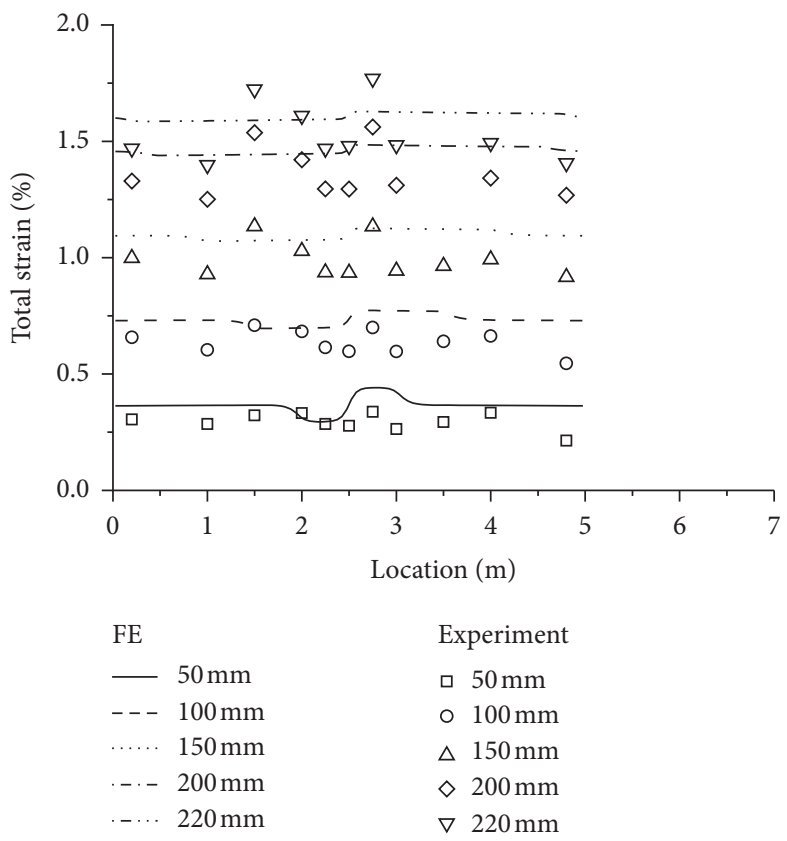

(c)

Figure 5: Comparison between finite element results and full-scale model test results: (a) axial strain; (b) bending strain; (c) total strain.

assess the effects of parameter uncertainties. MCS relies on repeatedly calculating a mathematical or empirical operator in which the variables are random with prescribed probability distributions [26, 27]. It starts with characterization of parameter uncertainties. The uncertain parameters for the problem considered here involve the seabed offset $\Delta_{s}$, intersection angle $\beta$, anchored cable length $L_{a}$, soil critical friction angle $\phi$, effective unit weight $\gamma^{\prime}$, and cable burial depth $H$. The uncertainties are characterized by their respective probability distribution functions and associated parameters. Subsequently, $n_{0}$ sets of random samples are generated with the aid of the commercial software MATLAB [28]. For each set of random samples of $\Delta_{s}, \beta, L_{a}, \phi, \gamma^{\prime}$, and $H$, $\mathrm{FE}$ analysis is performed to investigate cable responses (i.e., maximum cable strain $\left.\varepsilon_{\text {max }}\right)$. The $\mathrm{FE}$ results are extracted using a user-defined python script. With the aid of MAT$\mathrm{LAB}$, this process is repeated until all $n_{0}$ sets of random samples are used, leading to $n_{0}$ sets of outputs (i.e., maximum cable strain $\varepsilon_{\max }$ ) obtained from MCS. Finally, a statistical analysis of the output is performed, such as 


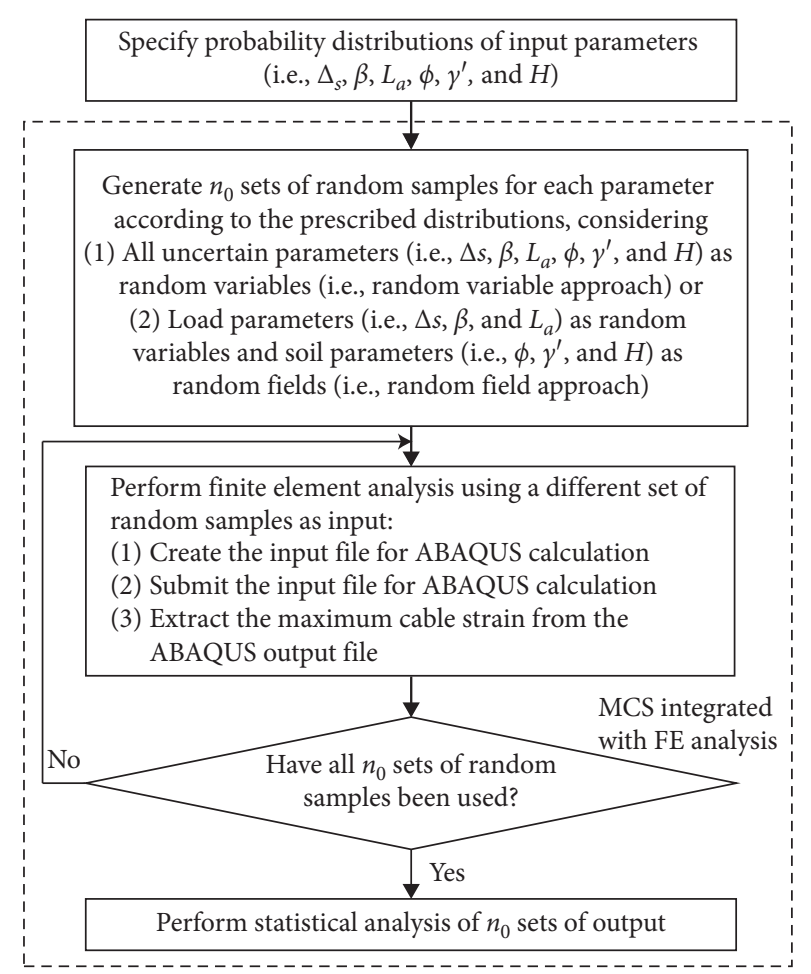

Figure 6: Probabilistic framework for assessment of parameter uncertainties.

characteristics of $\varepsilon_{\max }$ distribution and effects of various parameter uncertainties on cable damage probability. The cable damage probability $P(D)$ is estimated using the following equation:

$$
P(D)=\frac{n_{D}}{n_{0}}
$$

where $n_{D}$ is the number of damaged cable samples, in which the maximum cable strain $\varepsilon_{\text {max }}$ induced by seabed movements exceeds the allowable cable strain $\varepsilon_{\text {allo }}$.

\subsection{Characterization of Parameter Uncertainties.} Probability distributions of various parameters need to be determined for quantifying these uncertainties prior to implementing MCS. The parameters are divided into three groups: load parameters, soil parameters, and cable parameters. Load parameters include the seabed offset $\Delta_{s}$, the intersection angle $\beta$, and the anchored cable length $L_{a}$. Soil parameters refer to the soil friction angle $\phi$, the effective unit weight $\gamma^{\prime}$, and the cable burial depth $H$. Cable parameters include the cross section dimensions and the equivalent Young's modulus $E_{\text {equ. }}$. Note that submarine cables are designed and manufactured with quality control and assurance before deployment, and cable parameters are reasonably regarded as constants. The SA cable described previously is used here as an illustration example.

Table 1 summarizes all uncertain parameters $\left(\Delta_{s}, \beta, L_{a}, \phi\right.$, $\gamma^{\prime}$, and $H$ ) and their statistical characteristics considered in this study. Since there is little information about prevailing prior knowledge of parameters of $\Delta_{s}, \beta$, and $L_{a}$ on the site, they are modeled using uniform distributions with prescribed minimum and maximum values. For earthquakeinduced ground movements, Wells and Coppersmith [29] compiled an observational database based on historical earthquakes worldwide, according to whom the maximum observational value of average surface displacements induced by strike-slip faults is $8.0 \mathrm{~m}$ with an earthquake moment magnitude of 8.0 . Therefore, $8.0 \mathrm{~m}$ is taken as the maximum seabed offset $\Delta_{s}$ induced by earthquakes in this study. The minimum value of $\Delta_{s}$ should be larger than zero. Therefore, $\Delta_{s}$ is taken to follow a uniform distribution between $0 \mathrm{~m}$ and $8.0 \mathrm{~m}$. The intersection angle $\beta$ is taken to be uniformly distributed over a large range from $5^{\circ}$ to $90^{\circ}$. For the anchored cable length, the maximum value $L_{a \text {, max }}$ is determined to make sure that there is no significant influence on the maximum cable strain if $L_{a}$ is larger than $L_{a \text {,max }}$. Considering the most unfavorable condition among the possible seabed offsets $\Delta_{s}$ and intersection angles (i.e., $\Delta_{s}$ is equal to the maximum value of $8.0 \mathrm{~m}$ and $\beta$ is equal to its minim value of $5^{\circ}$ ), it is found that $L_{a, \max }=2,000 \mathrm{~m}$ is enough to meet the requirement. Thus, the maximum value of $L_{a}$ is selected as $2,000 \mathrm{~m}$, and $L_{a}$ starts from a very small value (e.g., $1 \mathrm{~m}$ ). Therefore, $L_{a}$ is uniformly distributed between $1 \mathrm{~m}$ and $2,000 \mathrm{~m}$.

For soil parameters, the effective friction angle $\phi$ and effective unit weight $\gamma^{\prime}$ can be characterized using either normal or lognormal distributions [26, 30]. In this study, normal distributions are employed. The mean values of $\phi$ and $\gamma^{\prime}$ are selected as $35^{\circ}$ and $10.2 \mathrm{kN} / \mathrm{m}^{3}$, respectively. Both coefficients of variation (COVs) of $\phi$ and $\gamma^{\prime}$ are estimated as 0.09. The adopted mean values and COVs are based on the typical values reported in literature [31-33]. In general, the cable burial depth $H$ is less than $1 \mathrm{~m}$ [2]. For illustration of cable-soil interaction, the minimum value of $H$ is assumed to be $0.1 \mathrm{~m}$ beneath the seabed. Thus, the cable burial depth $H$ is taken to follow a uniform distribution between $0.1 \mathrm{~m}$ and $1 \mathrm{~m}$.

3.3. Monte Carlo Simulation. The MCS integrated with FE analysis is preformed to evaluate effects of parameter uncertainties on cable responses to lateral seabed movements. Based on the generated random samples, the axial and transverse horizontal soil resistances (i.e., $t_{u}$ and $p_{u}$, respectively) are calculated using equations (1) and (2). Then, the deterministic FE model is implemented for every MCS sample. The maximum cable strain $\varepsilon_{\max }$ is obtained from FE analysis and used as an index to represent cable responses to seabed movements. The uncertainties of various parameters are reflected in the variation of $\varepsilon_{\text {max }}$.

\section{Results and Discussion}

4.1. Sensitivity of MCS Numbers. The sensitivity of results to the number of MCS samples is investigated. Figure 7 shows the variation of the cable damage probability with the number of MCS. As expected, simulation results converge to a stable value as the number of simulation increases. It can be seen that 10000 simulations are sufficient to give reliable and 
TABLE 1: Summary of uncertain parameters and their statistical characteristics.

\begin{tabular}{lc}
\hline Parameters & Distribution* \\
\hline Load parameters & \\
Seabed offset $\Delta_{s}$ & Uniform distribution: $0 \mathrm{~m} \sim 8 \mathrm{~m}$ \\
Intersection angle $\beta$ & Uniform distribution: $5^{\circ} \sim 90^{\circ}$ \\
Anchored cable length $L_{a}$ & Uniform distribution: $1 \mathrm{~m} \sim 2000 \mathrm{~m}$ \\
\hline Soil parameters & \\
Effective friction angle $\phi$ & Normal distribution: $\mu_{\phi}=35^{\circ}, \mathrm{COV}_{\phi}=0.09$ \\
Effective unit weight $\gamma^{\prime}$ & Normal distribution: $\mu_{\gamma}^{\prime}=10.2 \mathrm{kN} / \mathrm{m}^{3}, \mathrm{COV}_{\gamma^{\prime}}=0.09$ \\
Cable burial depth $H$ & Uniform distribution: $0.1 \mathrm{~m} \sim 1 \mathrm{~m}$ \\
\hline
\end{tabular}

${ }^{*} \mu$ and COV represent the mean value and the coefficient of variation, respectively.

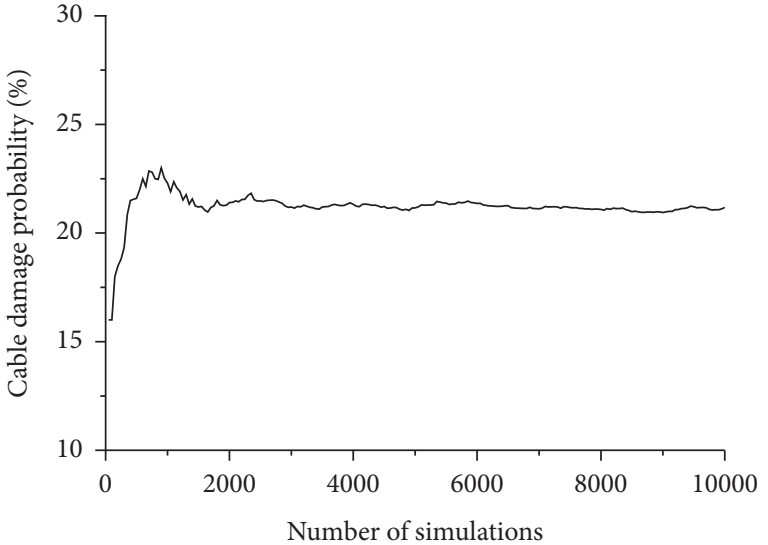

FIgURE 7: Influence of the number of Monte Carlo simulations on cable damage probability.

reproducible results. Therefore, 10000 sets of samples are generated for each random variable. The histogram of the maximum cable strain $\varepsilon_{\max }$ obtained from the 10000 MCS samples through FE analysis is presented in Figure 8. It shows that more than $85 \%$ of the $\varepsilon_{\max }$ values are distributed between $0 \%$ and $1 \%$. As $\varepsilon_{\max }$ increases, the normalized frequency of $\varepsilon_{\max }$ decreases and tends to be zero. The allowable cable strain $\varepsilon_{\text {allo }}$ (i.e., $0.72 \%$ ) is also plotted in Figure 8.

Statistical analysis indicates that there are 2118 sets of damaged MCS samples among the total 10000 samples. According to equation (3), the cable damage probability is calculated as $2118 / 10000=21.18 \%$. In other words, given the various and complex submarine environments and parameter uncertainties involved in cable responses to seabed movements, the majority (i.e., about $80 \%$ ) of submarine telecommunication cables are safe from the threat of seabed movements. This is consistent with the fact that only a small percentage of submarine telecommunication cables have been damaged due to earthquake effects [2].

4.2. Hypothesis Test. To identify and prioritize the effect of various parameter uncertainties on the probability of cable damage, probabilistic failure analysis is performed using a hypothesis test [34]. The effects of various parameter uncertainties on the cable damage probability are prioritized by statistically comparing damaged samples with their respective nominal (unconditional) samples. If the mean of an

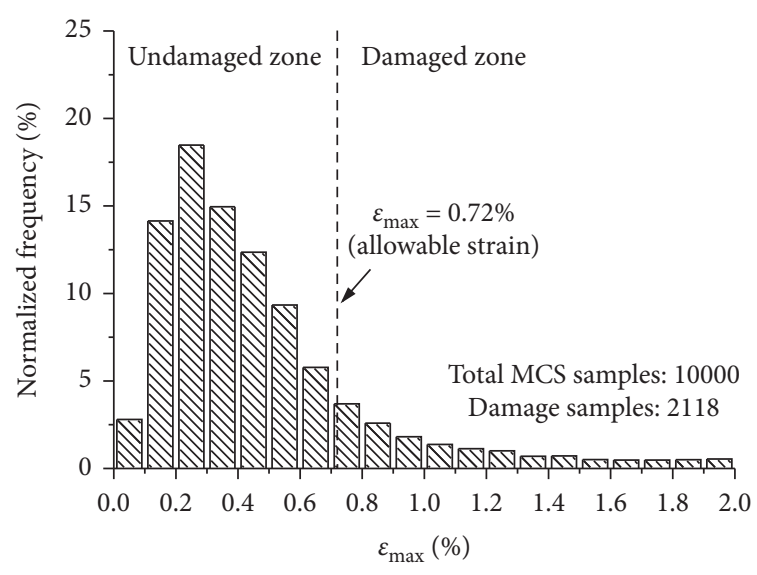

FIgURE 8: Histogram of the maximum cable strain $\varepsilon_{\max }$.

uncertain parameter has significant influence on the probability of cable damage, the mean $\mu$ of damaged samples of the parameter differs considerably from the mean $\mu_{0}$ of its unconditional samples. A pair of statistical hypotheses (i.e., a null hypothesis $H_{0}$ and alternative hypothesis $H_{A}$ ) are stated as follows [34]:

$$
\begin{aligned}
& H_{0}: \mu=\mu_{0}, \\
& H_{A}: \mu \neq \mu_{0} .
\end{aligned}
$$

Then, the hypothesis test statistic $z$ of the $Z$-test is formulated as [34]

$$
z=\frac{\mu-\mu_{0}}{\sigma / \sqrt{n}}
$$

where $\sigma$ is the standard deviation of the uncertain parameter and $n$ is the number of damaged samples. A large absolute value of $z$ means that the damaged sample mean $\mu_{0}$ deviates significantly from the unconditional mean $\mu$ of the parameter. In such a case, parameter uncertainty has a significant effect on cable damage probability. Therefore, the absolute value of $z$ is taken as an index to measure the effects of the uncertain parameters on cable damage probability and furthermore to prioritize their relative effects on cable damage probability [34].

Based on the damage MCS samples, the hypothesis test statistic $z$ defined in equation (5) is calculated. The calculation results of all uncertain parameters (i.e., $\Delta_{s}, \beta, L_{a}, \phi, \gamma^{\prime}$, and $H$ ) are illustrated in Figure 9. It shows that the absolute 


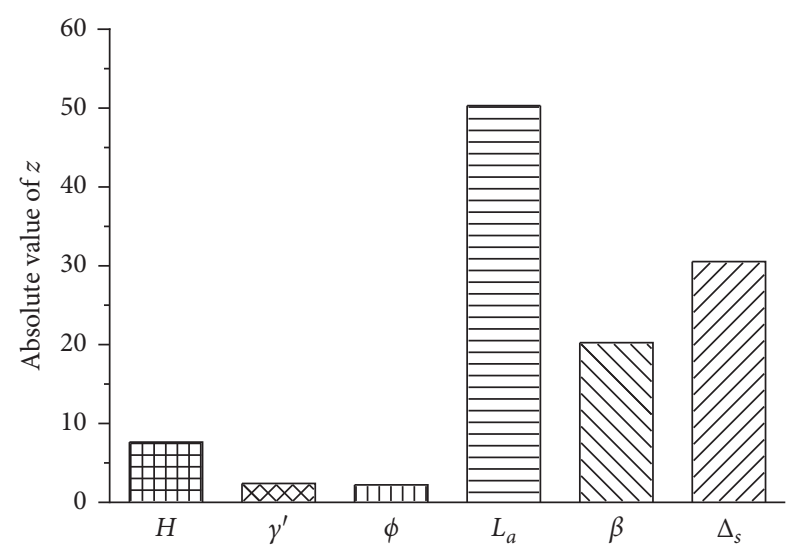

FIgURE 9: Summary of absolute values of $z$.

value of $z$ reaches its maximum value of about 50 for the anchored cable length $L_{a}$. The minimum $z$ value is about 2 for the soil friction angle $\phi$ and effective unit weight $\gamma^{\prime}$. This suggests that the uncertainty of $L_{a}$ has the most significant effect on the cable damage probability, while the effects of uncertainties of $\phi, \gamma^{\prime}$, and $H$ are insignificant.

4.3. Bayesian Analysis. The effects of various parameter uncertainties on the probability of cable damage can also be quantified by statistically comparing damaged samples with their respective nominal (unconditional) samples. If the uncertainty of a parameter has a significant effect on cable damage probability, the distribution of the parameter in damaged samples (i.e., conditional distribution) should be considerably different from its unconditional distribution. In Bayes' theorem, this is mathematically expressed as [26]

$$
P(D \mid \theta)=\frac{P(\theta \mid D) P(D)}{P(\theta)}
$$

where $\theta$ denotes an uncertain parameter; $P(D \mid \theta)$ is the conditional probability of cable damage for a given $\theta$ value; $P(D)$ is the cable damage probability that is directly obtained by dividing the number of damaged samples by the total number of MCS samples; $P(\theta \mid D)$ is the conditional probability of $\theta$ given that the cable has been damaged; and $P(\theta)$ is the unconditional probability of $\theta$.

Equation (6) implies that if $P(\theta \mid D)$ changes in a similar manner to $P(\theta), P(D \mid \theta)$ will be insensitive to $\theta$. This means that the uncertainty of parameter $\theta$ on cable damage probability is minimal. Therefore, the difference between the conditional probability distribution $P(\theta \mid D)$ and the unconditional probability $P(\theta)$ of an uncertain parameter reveals the influence of the uncertain parameter $\theta$ on cable damage probability [34].

Figure 10 presents the comparison between the conditional probability distributions of uncertain parameters (i.e., $P\left(L_{a} \mid D\right), P\left(\Delta_{\mathrm{s}} \mid D\right), P(\beta \mid D), P(\phi \mid D), P\left(\gamma^{\prime} \mid D\right)$, and $\left.P(H \mid D)\right)$ and their unconditional probability distributions (i.e., $P\left(L_{a}\right)$, $P\left(\Delta_{\mathrm{s}}\right), P(\beta), P(\phi), P\left(\gamma^{\prime}\right)$, and $\left.P(H)\right)$. It indicates that the conditional probability distributions of load parameters (i.e., $P\left(L_{a} \mid D\right), P\left(\Delta_{s} \mid D\right)$, and $\left.P(\beta \mid D)\right)$ differ significantly from their unconditional probability distributions (i.e., $P\left(L_{a}\right), P\left(\Delta_{\mathrm{s}}\right)$, and $P(\beta)$ ) (see Figures $10(\mathrm{a})-10(\mathrm{c})$ ). The difference between $P\left(L_{a} \mid D\right)$ and $P\left(L_{a}\right)$ is the largest, which reflects the paramount importance of uncertainty of $L_{a}$ for cable damage probability. In contrast, there is only a slight difference between the conditional and unconditional probability distributions of soil parameter (i.e., $\phi, \gamma^{\prime}$, and $H$ ) (see Figures $10(\mathrm{~d})-10(\mathrm{f}))$. This is reasonably consistent with the results from the statistical hypothesis testing.

4.4. Effect of Spatial Variability. Soil properties (e.g., soil friction angle $\phi$ and effective unit weight $\gamma^{\prime}$ ) may exhibit spatial variability and correlation depending on the formation process of soil, such as the properties of the parent material, erosion of seawater, and the sedimentation conditions. In addition, the cable burial depth $H$ may vary in space along the cable due to sediment accumulation or submarine landslides [2].

To investigate the effect of spatial variability of $\phi, \gamma^{\prime}$, and $H$, they are modeled using random fields spatially varying along the cable axial direction. An exponential correlation function is used to model the correlation structure, and the correlation coefficients of $\phi, \gamma^{\prime}$, and $H$ between locations $i$ and $j$ are expressed as [35-37]

$$
\rho_{i, j}=\exp \left(-\frac{2 \Delta l}{\lambda}\right),
$$

where $\lambda$ is the correlation length or scale of fluctuation along the horizontal direction and $\Delta l$ is the separation distance between locations $i$ and $j$. The correlation length $\lambda$ is used to describe the spatial variability of a random field. A large $\lambda$ means that soil properties vary relatively slowly in space. In other words, soil properties are highly correlated along a spatial direction. In contrast, a small $\lambda$ reflects that soil properties fluctuate very rapidly in space. MCS samples of random fields (i.e., $\phi, \gamma^{\prime}$, and $H$ ) are generated using the Karhunen-Loeve (K-L) expansion with prescribed probability distributions and correlation lengths, which is applicable to both Gaussian and non-Gaussian random fields $[38,39]$.

As suggested in the previous sections, the effects of uncertainties in load parameters such as $L_{a}, \beta$, and $\Delta_{s}$ are more significant than those of soil properties of $\phi, \gamma^{\prime}$, and $H$. However, once a seabed movement occurs, the values of $\Delta_{s}$, $\beta$, and $L_{a}$ become somewhat certain, while $\phi, \gamma^{\prime}$, and $H$ may exhibit spatial variability in space along the cable axial direction. To further investigate the effect of the horizontal correlation length $\lambda$ of $\phi, \gamma^{\prime}$, and $H$, two cases are compared here as an example. The offset distance $\Delta_{s}$ is $4 \mathrm{~m}$ in both cases, and the intersection angle $\beta$ and anchored length $L_{a}$ are $45^{\circ}$ and $500 \mathrm{~m}$ and and $50^{\circ}$ and $400 \mathrm{~m}$, respectively, for Cases 1 and 2, as listed in Table 2. As can be seen, Case 2 leads to a smaller axial displacement $\Delta_{s} \cos \beta$, but its anchored length is shorter (see Figure 2). Therefore, it is unsure which case is the worse one. The values of $\phi, \gamma^{\prime}$, and $H$ are modeled through random fields, while $\phi$ and $\gamma^{\prime}$ follow normal distributions. The means and COVs of $\phi$ and $\gamma^{\prime}$ are $35^{\circ}$ and 0.09 , and $10.2 \mathrm{kN} / \mathrm{m}^{3}$ and 0.09 , respectively. $H$ is taken to follow a 

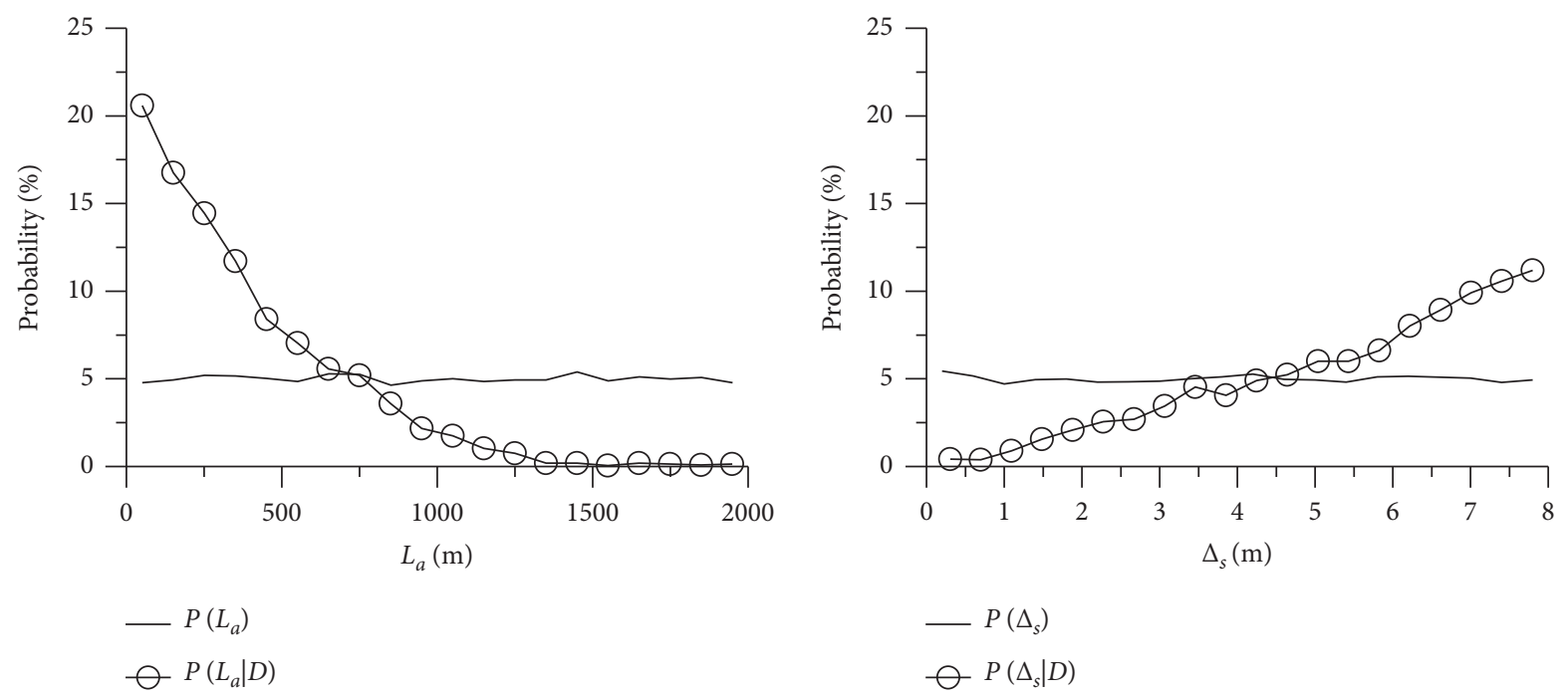

(a)

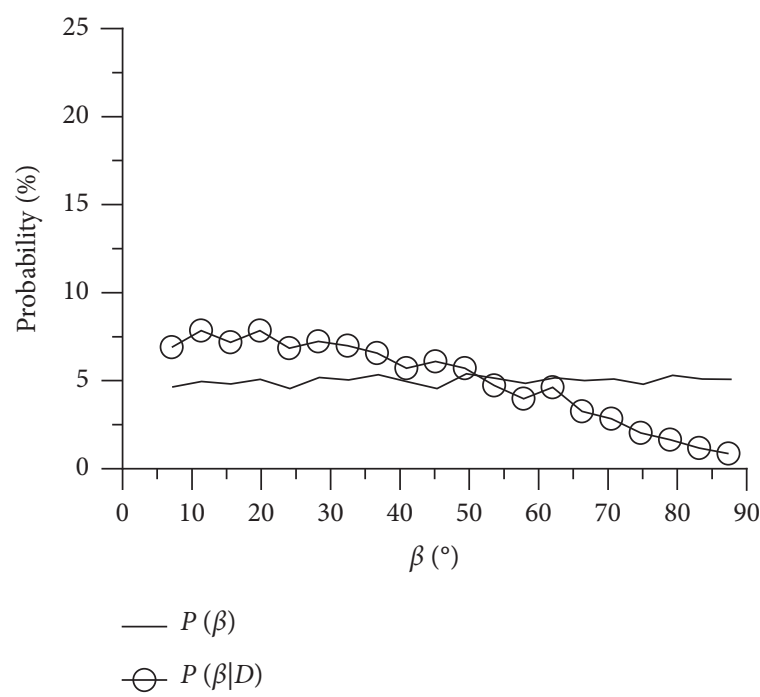

(c)
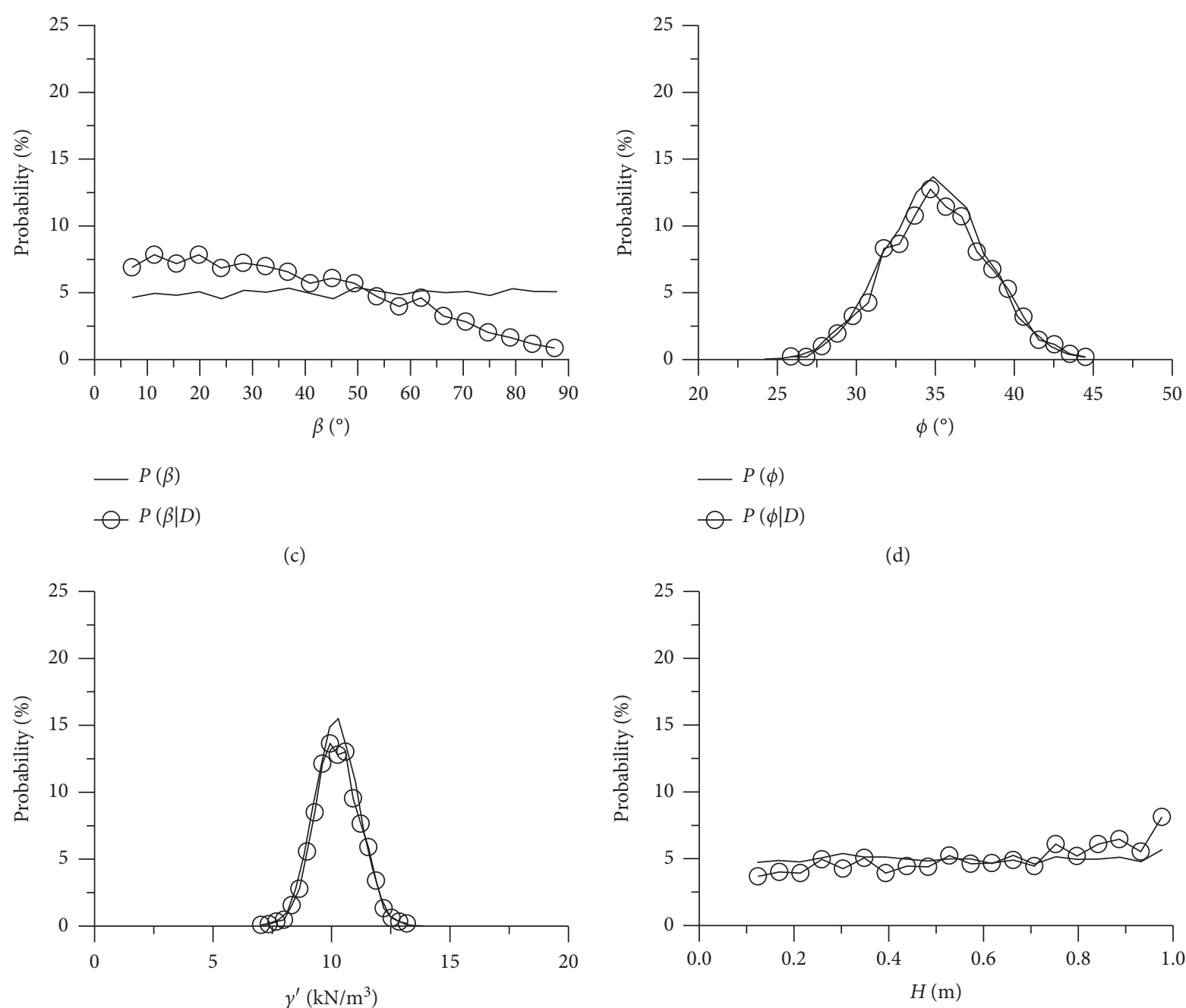

(d)

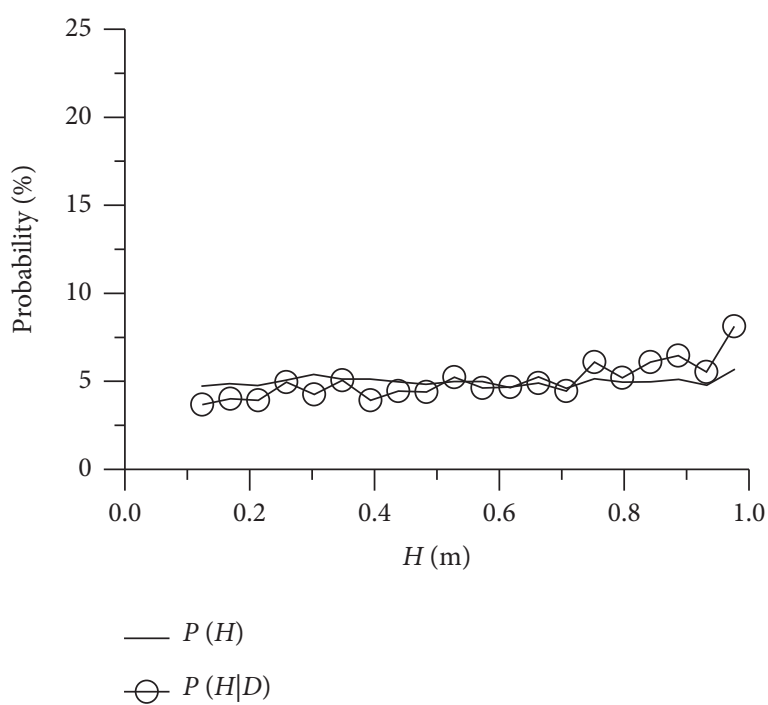

(f)

Figure 10: Conditional probability $P(\theta \mid D)$ for different $\theta$ : (a) $\theta=$ anchored cable length, $L_{a}$; (b) $\theta=$ seabed offset, $\Delta s$; (c) $\theta=$ intersection angle, $\beta$; (d) $\theta=$ soil friction angle, $\phi$; (e) $\theta=$ effective soil unit weight, $\gamma^{\prime}$; (f) $\theta=$ cable burial depth, $H$. 
TABLe 2: Parameters for investigating the effect of correlation length.

\begin{tabular}{lcc}
\hline Parameters & Values \\
\hline Seabed offset $\Delta_{s}(\mathrm{~m})$ & Case 1 & Case 2 \\
Intersection angle $\beta\left(^{\circ}\right)$ & 4 & 4 \\
Anchored cable length $L_{a}(\mathrm{~m})$ & 45 & 50 \\
Effective friction angle $\phi\left({ }^{\circ}\right)$ & 500 & 400 \\
Effective unit weight $\gamma^{\prime}\left(\mathrm{kN} / \mathrm{m}^{3}\right)$ & Normal distribution: $\mu_{\phi}=35^{\circ}, \mathrm{COV}_{\phi}=0.09$ \\
Cable burial depth $H(\mathrm{~m})$ & Normal distribution: $\mu_{\gamma^{\prime}}=10.2 \mathrm{kN} / \mathrm{m}^{3}, \mathrm{COV}_{\gamma^{\prime}}=0.09$ \\
\hline
\end{tabular}

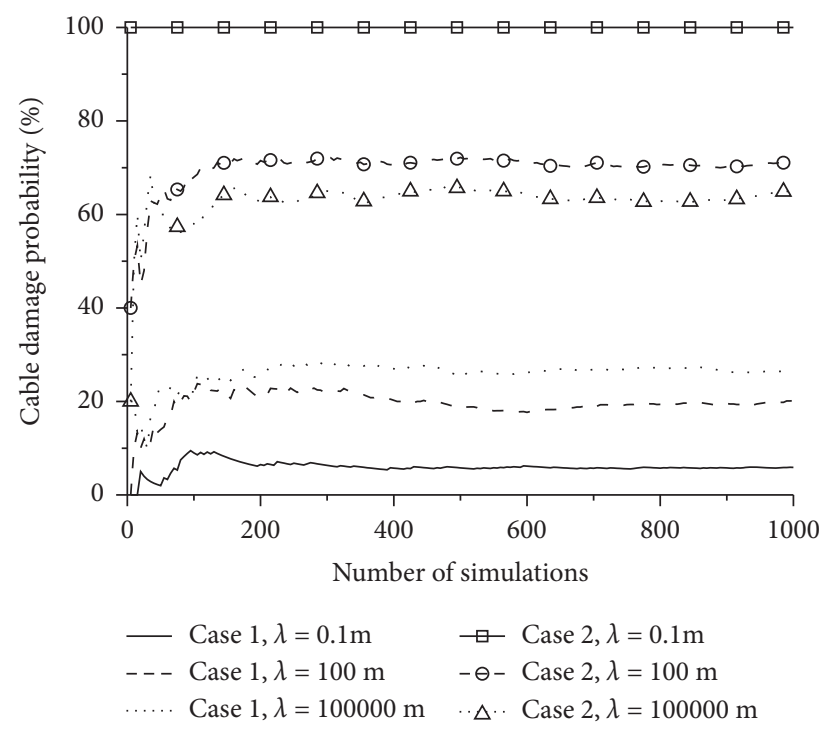

Figure 11: Influence of the number of MCS for Case 1 and Case 2 with different $\lambda$.

uniform distribution with the minimum value of $0.1 \mathrm{~m}$ and maximum value of $1 \mathrm{~m}$.

According to the previous study [31], the horizontal correlation length $\lambda$ typically varies from $40 \mathrm{~m}$ to $60 \mathrm{~m}$, which is much larger than the vertical correlation length (i.e., $2 \sim 10 \mathrm{~m}$ ) due to the soil depositional history. Therefore, the horizontal correlation length $\lambda$ here varies over a wide range, including 0.1 (i.e., approximated as 0 for a mutually independent case), 1, 10, 40, 100, 200, 1000, 10000, and $100,000 \mathrm{~m}$ (i.e., approximated as $\infty$ for a fully correlated case), respectively. The convergence of MCS results to the number of simulations for the example Cases 1 and 2 is examined using three different $\lambda$ values (i.e., $\lambda=0.1,100$, and $100,000 \mathrm{~m})$. As shown in Figure 11, the cable damage probability curves nearly become stable after 500 simulations. This is considerably different from the results of Section 4.1 (see Figure 7), in which all parameters are taken as random variables. To further improve the precision and consider the computing effort, 1000 simulations are used in the following analysis, which can provide a reliable estimation of the cable damage probability.

Figure 12 presents the variation of the mean and standard deviation of $\varepsilon_{\max }$ with $\lambda$. As indicated, the mean of $\varepsilon_{\max }$ almost remains constant at about $0.68 \%$ for Case 1 and $0.76 \%$ for Case 2 , while the standard deviation of $\varepsilon_{\max }$ increases slowly from about $0.01 \%$ to $0.07 \%$ for both cases when $\lambda$ increases from $0.1 \mathrm{~m}$ to $100,000 \mathrm{~m}$. It also shows that ignoring spatial correlation (i.e., $\lambda=0.1$ in this study) leads to underestimation of the standard deviation of $\varepsilon_{\text {max }}$.

The effect of spatial variability on the cable damage probability is shown in Figure 13. For Case 1, the cable damage probability increases steadily from $6 \%$ to $27 \%$ when $\lambda$ increases from 0.1 to $100,000 \mathrm{~m}$. In contrast, for Case 2, the cable damage probability decreases from $100 \%$ to $68 \%$ when $\lambda$ increases from 0.1 to $100,000 \mathrm{~m}$. It suggests that the spatial variability has a significant influence on the cable damage probability. The assumption that the soil parameters $\left(\phi, \gamma^{\prime}\right.$, and $H$ ) are fully correlated (i.e., the single random variable approach) may lead to underestimation of cable damage probability for cables that are about to fail or overestimation for cables that are considered to have adequate safety.

This phenomenon can be interpreted through the cumulative distribution function (CDF) of $\varepsilon_{\max }$. Figure 14 illustrates CDFs of $\varepsilon_{\max }$ for Cases 1 and 2 with $\lambda=10,100$, and $1000 \mathrm{~m}$. Since the standard deviation of $\varepsilon_{\max }$ increases with $\lambda$ (see Figure 12), the CDF curves become flat when $\lambda$ increases. For Case 1 with adequate safety, the allowable strain $\varepsilon_{\text {allo }}$ locates in the right tail of the CDF curve. As $\lambda$ increases, the probability of $\varepsilon_{\max }$ smaller than $\varepsilon_{\text {allo }}$ (i.e., undamaged samples) decreases gradually. In other words, the number of undamaged samples in Case 1 decreases when the correlation length $\lambda$ increases. Thus, the damaged samples and the cable damage probability increase as $\lambda$ increases. In contrast, for Case 2 in which the cable is about 


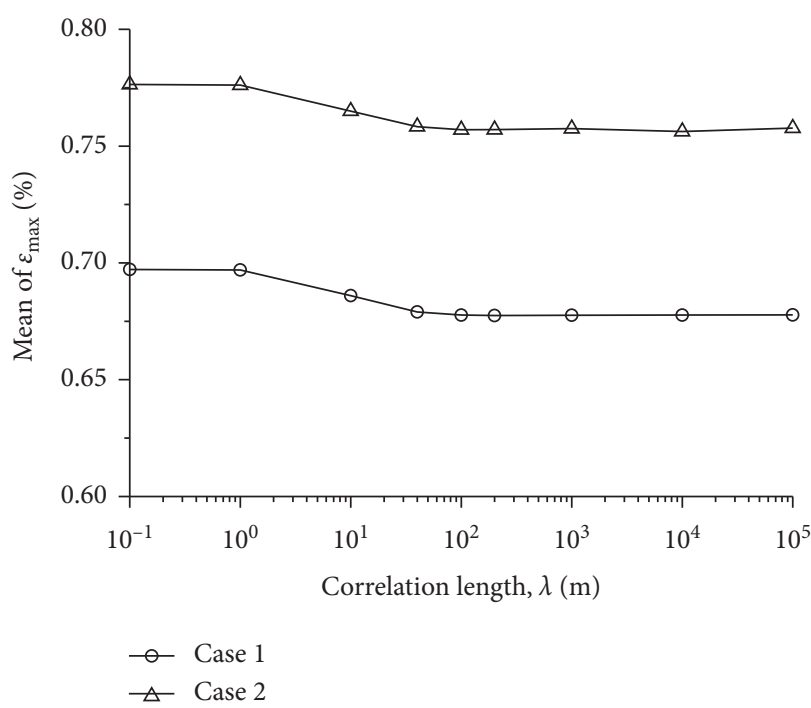

(a)

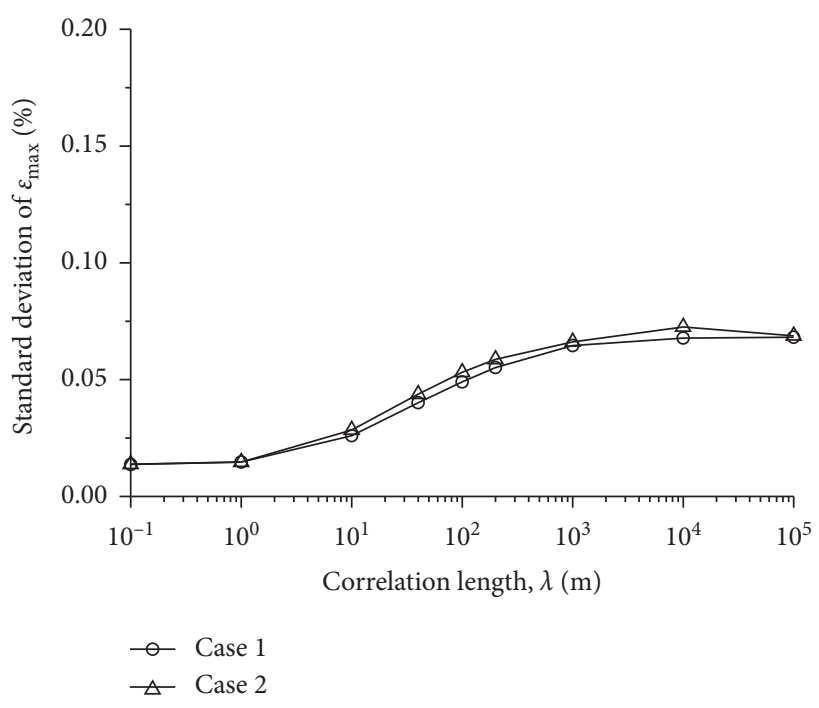

(b)

FIGURE 12: Relationship between correlation length and statistics of the maximum cable strain $\varepsilon_{\max }$ : (a) mean of $\varepsilon_{\max }$; (b) standard deviation of $\varepsilon_{\max }$.

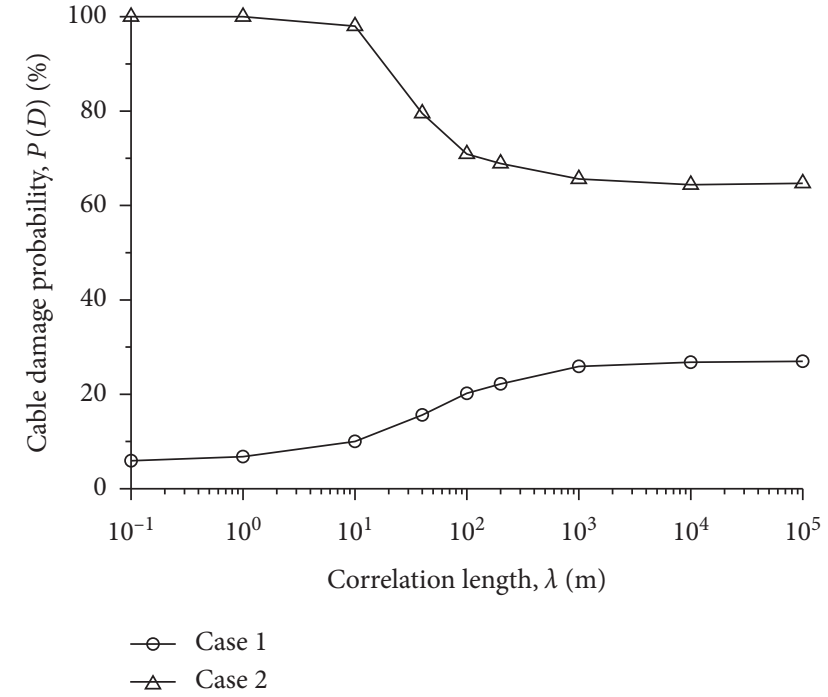

FIGURE 13: Effect of spatial variability on the cable damage probability.

to fail, the value of $\varepsilon_{\text {allo }}$ falls in the left tail of the CDF curve. This leads to the decrease of cable damage probability as $\lambda$ increases, as shown in Figure 13. Such an effect is similar to the effect of spatial variability on the slope failure probability, as reported in the literature [40-43]. In summary, the effect of correlation length depends on the safety status of cables and the location of $\varepsilon_{\text {allo }}$ on the CDF curve of $\varepsilon_{\text {max }}$.

\section{Summary and Conclusions}

Using random finite element method, this paper conducted a probabilistic analysis for assessment of parameter uncertainties on cable responses to lateral seabed movements. A beam-on-spring FE model was developed

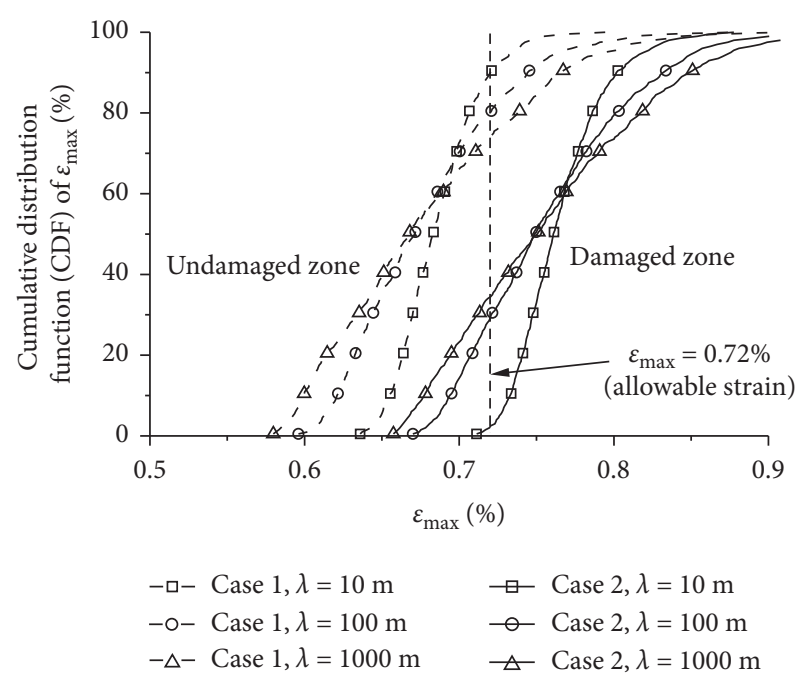

FIGURE 14: Cumulative distribution function (CDF) of the maximum cable strain $\varepsilon_{\max }$.

as a deterministic approach to investigate cable responses to lateral seabed movements, and the uncertain parameters involved in FE analysis (i.e., seabed offset $\Delta_{s}$, intersection angle $\beta$, anchored cable length $L_{a}$, soil friction angle $\phi$, effective unit weight $\gamma^{\prime}$, and cable burial depth $H$ ) were characterized with corresponding probability distributions according to their physical significance. Then MCS was implemented to investigate the effect of parameter uncertainties on submarine cable responses. Subsequently, statistical hypothesis testing was performed to identify and prioritize the effect of various parameter uncertainties on the probability of cable damage. Finally, effects of spatial variability of $\phi, \gamma^{\prime}$, and $H$ were also explored. The concluding remarks can be summarized as follows: 
(1) The proposed FE model was validated by a largescale physical test, and a good agreement was obtained between the results of FE analysis and the physical model test. It suggests that the axial strain dominates the total cable strain, while the bending strain is insignificant.

(2) Analysis of statistical hypothesis testing shows that the uncertainty of $L_{a}$ has the most significant effect on cable damage probability, while the effects of the uncertainties of $\phi, \gamma^{\prime}$, and $H$ are insignificant. This is also verified by statistically comparing damaged samples with their respective unconditional samples in Bayes' theorem.

(3) The correlation length of $\phi, \gamma^{\prime}$, and $H$ has significant effects on the standard deviation of $\varepsilon_{\max }$ and cable damage probability; but it has a minor effect on the mean of $\varepsilon_{\max }$. When the spatial variability is ignored by assuming perfect correlation, the cable damage probability may be underestimated or overestimated depending on the safety status of cables and the location of the allowable cable strain $\varepsilon_{\text {allo }}$ on the CDF curve of $\varepsilon_{\text {max }}$.

\section{Data Availability}

The data used to support the findings of this study are available from the corresponding author upon request.

\section{Conflicts of Interest}

The authors declare that they have no conflicts of interest.

\section{Acknowledgments}

The work described in this paper was supported by grants from the Research Grants Council of the Hong Kong Special Administrative Region, China (Project No. 9042331 (CityU 11225216) and Project No. 8779012 (T22-603/15N)). The financial support is gratefully acknowledged.

\section{References}

[1] J. Chesnoy, Undersea Fiber Communication Systems, Academic Press, San Diego, CA, USA, Second edition, 2015.

[2] L. Carter, D. Burnett, S. Drew et al., "Submarine cables and the oceans: connecting the world," UNEP-WCMC Biodiversity Series No. 31, ICPC/UNEP/UNEP-WCMC, Cambridge, UK, 2009.

[3] F. Wang, Z. Dai, Y. Nakahara, and T. Sonoyama, "Experimental study on impact behavior of submarine landslides on undersea communication cables," Ocean Engineering, vol. 148, no. 15, pp. 530-537, 2018.

[4] R. Gavey, L. Carter, J. T. Liu et al., "Frequent sediment density flows during 2006 to 2015, triggered by competing seismic and weather events: observations from subsea cable breaks off southern Taiwan," Marine Geology, vol. 384, no. 1, pp. 147-158, 2017.

[5] Y.-S. Kuo, K.-J. Chong, Y.-H. Tseng, C.-W. Hsu, and C.-S. Lin, "Assessment on liquefaction potential of seabed soil in Chang-Bin Offshore wind farm considering parametric uncertainty of standard penetration tests," Engineering Geology, vol. 267, no. 20, Article ID 105497, 2020.
[6] Y. Cheng and S. Akkar, "Probabilistic permanent fault displacement hazard via Monte Carlo simulation and its consideration for the probabilistic risk assessment of buried continuous steel pipelines," Earthquake Engineering \& Structural Dynamics, vol. 46, no. 4, pp. 605-620, 2017.

[7] ITU, Characteristics of Optical Fibre Submarine Cables, International Telecommunication Union, Geneva, Switzerland, 2010.

[8] ITU, Definition of Terms Relevant to Optical Fibre Submarine Cable Systems, International Telecommunication Union, Geneva, Switzerland, 2016.

[9] Alcatel-Lucent, Eastern Africa Submarine Cable System (Eassy): Oalc-4 Submarine Cable Technical Description, Alcatel-Lucent Submarine Networks, Boulogne-Billancourt, France, 2008.

[10] ALA, Guidelines for the Design of Buried Steel Pipe, ASCE, Reston, VA, USA, 2005.

[11] X. Zhang and C. G. Soares, "Lateral buckling analysis of subsea pipelines on nonlinear foundation," Ocean Engineering, vol. 186, no. 15, Article ID 106085, 2019.

[12] L. Wang and R. Liu, "The effect of a berm on the lateral resistance of a shallow pipeline buried in sand," Ocean Engineering, vol. 121, pp. 13-23, 2016.

[13] K. Roy, B. Hawlader, S. Kenny, and I. Moore, "Finite element modeling of lateral pipeline-soil interactions in dense sand," Canadian Geotechnical Journal, vol. 53, no. 3, pp. 490-504, 2016.

[14] C. H. Trautmann and T. D. O'Rourke, "Lateral force-displacement response of buried pipe," Journal of Geotechnical Engineering, vol. 111, no. 9, pp. 1077-1092, 1985.

[15] X. Qin, P. Ni, and Y.-J. Du, "Buried rigid pipe-soil interaction in dense and medium sand backfills under downward relative movement: 2D finite element analysis," Transportation Geotechnics, vol. 21, Article ID 100286, 2019.

[16] J. Shi, J. Wei, C. W. W. Ng, and H. Lu, "Stress transfer mechanisms and settlement of a floating pile due to adjacent multi-propped deep excavation in dry sand," Computers and Geotechnics, vol. 116, Article ID 103216, 2019.

[17] J. Shi, Z. Fu, and W. Guo, "Investigation of geometric effects on three-dimensional tunnel deformation mechanisms due to basement excavation," Computers and Geotechnics, vol. 106, pp. 118-116, 2019.

[18] X. Qin and P. Ni, "Kinematics of bell-spigot joints in vitrified clay pipelines under differential ground movement," Tunnelling and Underground Space Technology, vol. 91, Article ID 103005, 2019.

[19] Dassault Systèmes, ABAQUS, Providence, RI, USA, 2013.

[20] Y. Wang, J. Shi, and C. W. W. Ng, "Numerical modeling of tunneling effect on buried pipelines," Canadian Geotechnical Journal, vol. 48, no. 7, pp. 1125-1137, 2011.

[21] J. Shi, Y. Wang, and C. W. W. Ng, "Buried pipeline responses to ground displacements induced by adjacent static pipe bursting," Canadian Geotechnical Journal, vol. 50, no. 5, pp. 481-492, 2013.

[22] J. Shi, Y. Wang, and C. W. W. Ng, "Numerical parametric study of tunneling-induced joint rotation angle in jointed pipelines," Canadian Geotechnical Journal, vol. 53, no. 12, pp. 2058-2071, 2016.

[23] P. Ni and S. Mangalathu, "Fragility analysis of gray iron pipelines subjected to tunneling induced ground settlement," Tunnelling and Underground Space Technology, vol. 76, pp. 133-144, 2018.

[24] J. Shi, C. Ding, C. W. W. Ng, H. Lu, and L. Chen, "Effects of overconsolidation ratio on tunnel responses due to overlying 
basement excavation in clay," Tunnelling and Underground Space Technology, vol. 97, Article ID 103247, 2020.

[25] C. Fu, Responses of Submarine Telecommunication Cables to Earthquakes, Ph.D. thesis, City University of Hong Kong, Kowloon Tong, Hong Kong, 2019.

[26] Y. Wang, "Reliability-based design of spread foundations by Monte Carlo simulations," Géotechnique, vol. 61, no. 8, pp. 677-685, 2011.

[27] Y. Wang, S.-K. Au, and F. H. Kulhawy, "Expanded reliabilitybased design approach for drilled shafts," Journal of Geotechnical and Geoenvironmental Engineering, vol. 137, no. 2, pp. 140-149, 2011.

[28] MATLAB, MathWorks, Inc.MATLAB, Natick, MA, USA, 2014.

[29] D. L. Wells and K. J. Coppersmith, "New empirical relationships among magnitude, rupture length, rupture width, rupture area, and surface displacement," Bulletin of the Seismological Society of America, vol. 84, no. 4, pp. 974-1002, 1994.

[30] Y. Wang, T. Zhao, and Z. Cao, "Site-specific probability distribution of geotechnical properties," Computers and Geotechnics, vol. 70, pp. 159-168, 2015.

[31] K.-K. Phoon and F. H. Kulhawy, "Characterization of geotechnical variability," Canadian Geotechnical Journal, vol. 36, no. 4, pp. 612-624, 1999.

[32] K.-K. Phoon and F. H. Kulhawy, "Evaluation of geotechnical property variability," Canadian Geotechnical Journal, vol. 36, no. 4, pp. 625-639, 1999.

[33] Z. Cao, Y. Wang, and D. Li, "Quantification of prior knowledge in geotechnical site characterization," Engineering Geology, vol. 203, no. 25, pp. 107-116, 2015.

[34] Y. Wang, Z. Cao, and S.-K. Au, "Efficient Monte Carlo Simulation of parameter sensitivity in probabilistic slope stability analysis," Computers and Geotechnics, vol. 37, no. 7-8, pp. 1015-1022, 2010.

[35] G. A. Fenton, "Estimation for stochastic soil models," Journal of Geotechnical and Geoenvironmental Engineering, vol. 125, no. 6, pp. 470-485, 1999.

[36] Y. Wang, S.-K. Au, and Z. Cao, "Bayesian approach for probabilistic characterization of sand friction angles," Engineering Geology, vol. 114, no. 3-4, pp. 354-363, 2010.

[37] Y. Wang and Z. Cao, "Expanded reliability-based design of piles in spatially variable soil using efficient Monte Carlo simulations," Soils and Foundations, vol. 56, no. 3, pp. 820834, 2013.

[38] K.-K. Phoon, S.-T. Quek, and H. Huang, "Simulation of nonGaussian processes using fractile correlation," Probabilistic Engineering Mechanics, vol. 19, no. 4, pp. 287-292, 2004.

[39] K. K. Phoon, H. W. Huang, and S. T. Quek, "Simulation of strongly non-Gaussian processes using Karhunen-Loeve expansion," Probabilistic Engineering Mechanics, vol. 20, no. 2, pp. 188-198, 2005.

[40] D. V. Griffiths and G. A. Fenton, "Probabilistic slope stability analysis by finite elements," Journal of Geotechnical and Geoenvironmental Engineering, vol. 130, no. 5, pp. 507-518, 2004.

[41] S. E. Cho, "Effects of spatial variability of soil properties on slope stability," Engineering Geology, vol. 92, no. 3-4, pp. 97-109, 2007.

[42] Y. Wang, Z. Cao, and S.-K. Au, "Practical reliability analysis of slope stability by advanced Monte Carlo simulations in a spreadsheet," Canadian Geotechnical Journal, vol. 48, no. 1, pp. 162-172, 2011.
[43] S.-H. Jiang, D.-Q. Li, Z.-J. Cao, C.-B. Zhou, and K.-K. Phoon, "Efficient system reliability analysis of slope stability in spatially variable soils using Monte Carlo simulation," Journal of Geotechnical and Geoenvironmental Engineering, vol. 141, no. 2, Article ID 04014096, 2015. 